\title{
Violencia e imagen: o del siniestro círculo de las pasiones
}

\author{
Violence and Image: or the \\ Sinister Circle of Passions
}

\author{
Ciro Roldán (Colombia) \\ ciroroldan@hotmail.com \\ Universidad Nacional de Colombia
}

\begin{abstract}
Resumen
Este texto intenta integrar el enfoque del psicoanálisis sobre la muerte, la guerra y la violencia como destino o círculo siniestro del fenómeno humano con la reflexión filosófica suscitada acerca de la violencia como estado de naturaleza o necesidad. El porqué de la guerra como destino de las pulsiones: esa es la cuestión común de sus enfoques. Se derivan de este asunto otras cuestiones acerca de la existencia de fuerzas bipolares, cuya lucha constante y alianza periódica es responsable de la creación y la destrucción de todo el fenómeno de nuestra cultura. Este ciclo repetitivo y provocador de violencia real, a través de la violencia imaginaria y simbólica,
\end{abstract}

\begin{abstract}
The following text aims to integrate the psychoanalysis approach on death, war and violence as destination or sinister circle of the human phenomenon using philosophical reflection emerging from violence as a state of nature or necessity. The reason of war as destination of the drive: that is the common issue in its approaches. Some other aspects derive from this matter: the existence of bipolar forces which constant struggle and periodic alliance is responsible for the creation and the destruction of the entire phenomenon of our culture. This repetitive cycle, real violence-provoking through imaginary and symbolic violence, constricts to think whether this is constituent of
\end{abstract}

\begin{tabular}{ll}
\hline FECHA DE RECEPCIÓN: & 22 de agosto de 2012 \\
FECHA DE REVISIÓN: & 17 de octubre de 2012 \\
APROBACIÓN: & 19 de octubre de 2012
\end{tabular}

Para citar este artículo / to cite this article

Roldán, C. Violencia e imagen: o del siniestro círculo de las pasiones. Poliantea, 8(15), 137-170. 
obliga a pensar si ello es constitutivo de un círculo siniestro inevitable. Todo esto apunta a suponer que tras esa ambivalencia pulsional ante la ley existe una violencia primordial resistente y transgresora de todo orden, lo que hace inevitable el conflicto humano.

Surge así el plan inicial de la primera parte al tratar de reconstruir las grandes líneas de la pregunta actual por la guerra formulada al psicoanálisis y traída desde los inicios de la filosofía moderna de las pasiones inaugurada por Hobbes: esto culmina en una segunda parte cuando ello es vuelto objeto de discusión por Freud en sus textos posteriores a Más allá del principio del placer y Lo ominoso, pequeño volumen publicado en ese mismo año, 1919 - desapercibido hasta hace poco, cuando fue recuperado por corrientes filosófico-psicoanalíticas.

Al final se discute la hipótesis de una violencia transgresora latente de este destino ominoso.

Palabras clave: Violencia, imagen, ominoso, psicoanálisis. an inevitable sinister circle. This leads to assume that behind the drive's ambivalence there is a primordial, resistant and transgressive of all order violence, which makes the human conflict inevitable.

It rises from the initial plan of the first part when trying to reconstruct the great lines of the current question from the war formulated to psychoanalysis and brought from the origins of modern philosophy of the passions first outlined by Hobbes: This ends in a second part when it becomes object of discussion in Freud's subsequent texts to Beyond the Pleasure Principle and The Ominous, small volume published in that same year, 1919- inadvertent until not long ago- when it was recovered by philosophical-psychoanalytical trends. A hypothesis of a transgressive latent violence of this ominous destiny is finally discussed.

Keywords: Key Words: violence, image, ominous, psychoanalysis. 


\title{
Violencia e imagen: o del siniestro círculo de las pasiones
}

\begin{abstract}
Profesor de Filosofía de la Universidad Nacional de Colombia desde 1975. Profesor invitado de Universidad Javeriana, Libre y los Andes. Ha colaborado en revistas y periódicos nacionales y ha sido asesor cultural de la Cadena RCN. Ha publicado textos en la Universidad Nacional de Colombia en las revistas Ideas y Valores, Revista Colombiana de Psicología y Palimpsestus, de la que fue miembro fundador en el Consejo Editorial. Director y fundador del Centro Editorial de la Universidad Nacional y miembro del Consejo Superior de esta. Coautor de dos libros fundamentales: Lecciones de filosofía política, de la Universidad Externado de Colombia, y Crisis colombiana, de la Universidad Nacional. Su última publicación es Las estéticas de la vida: Schopenhaver, Nietzsche, Freud, de la Universidad Libre, publicación

en la que es compilador y autor. Ha sido conferencista en varios congresos nacionales de filosofía.
\end{abstract}

Ciro Roldán

\section{Nada más siniestro que el hombre}

Entendemos lo pavoroso (Unheimliche) como aquello que nos arranca de lo familiar (Heimlichen), es decir, de lo doméstico, habitual, corriente,

inofensivo. Lo pavoroso no nos permite estar en nuestra propia casa

(Einheimisch). En esto reside lo que subyuga. Pero el hombre es lo más pavoroso, porque no solo se conduce en medio de lo pavoroso así entendido, sino porque sale o se evade de los límites que al comienzo y la mayor parte de las veces, le son habituales y familiares: porque él entendido como el que hace violencia, transgrede los límites de lo familiar, siguiendo justamente la dirección de lo siniestro concebido como lo que subyuga.

HEIDEGGER 


\section{La pregunta dirigida al psicoanálisis: ¿por qué la guerra?}

El primer intento trata de mostrar el origen del problema de la violencia como propio de las pasiones humanas ¿Por qué la guerra? Fue el tema traído a colación en una serie de sugerencias hechas por Albert Einstein —en una carta que dirigió a Freud hace más o menos ochenta años- en la que el científico, preocupado por la guerra, le preguntaba a Freud su opinión acerca de la relación entre la guerra y las pulsiones humanas, al borde de la conflagración mundial, en pleno periodo de entreguerras y cuando se preparaba, desde 1930, la asonada de los nazis en Alemania, de donde ellos - como judíos - serían expulsados o al menos intentados de exilar de la memoria de su pueblo. Y en esa carta he encontrado un pequeño párrafo donde formula su pregunta Einstein a Freud en 1933, cuando se inicia el cruce de cartas de este epistolario. Allí Einstein reflexiona de esta forma:

Porque el hombre tiene dentro de sí un apetito de odio y destrucción. En épocas normales esta pasión existe en estado latente, y únicamente emerge en circunstancias inusuales; pero es relativamente sencillo ponerla en juego y exaltarla hasta el poder de una psicosis colectiva (Freud, 1979, t. XXII, p. 185).

Esta inquietud empieza a ser respondida por Freud de manera inicial en un párrafo que sintetiza su pensamiento sobre el final de la guerra y la base de la paz:

Aplicado a nuestro presente se llega al mismo resultado que usted obtuvo por un camino más corto, una prevención segura de las guerras sólo es posible si los hombres acuerdan la institución de una violencia central, encargada de entender en todos los conflictos de intereses. Evidentemente, se reúnen aquí dos exigencias: que se cree una instancia superior de esa índole y que se le otorgue el poder requerido (1979, t. XXII, p. 191).

Freud en esta respuesta teme desilusionar a Einstein, al que le dice que él sabe tanto de física como Einstein de psicoanálisis, pero que descree como Einstein de ese optimismo del hombre científico el cual confía en que hay algo más poderoso en los hombres que la simple apetencia vital, puesto que supone la existencia de algo más allá de ese apetito puramente destructivo, y así le pregunta: “ ¿Es posible controlar la evolución mental del hombre como para ponerlo a salvo de la psicosis 
del odio y la destructividad?" (1979, t. XXII, p. 185). Si la guerra parece acorde con la naturaleza bien fundada biológicamente y apenas es evitable en la práctica, entonces se puede dudar de que los hombres dispongan de una aptitud cultural que rechace la barbarie. Pero se pregunta Freud:

¿Por qué nos sublevamos tanto contra la guerra, usted y yo y tantos otros? ¿Por qué no la admitimos como una de las tantas penosas calamidades de la vida?... La respuesta sería: porque todo hombre tiene derecho a su propia vida, porque la guerra aniquila promisorias vidas humanas, pone al individuo en situaciones indignas, lo compele a matar a otro, cosa que él no quiere, destruye preciosos valores materiales, productos del trabajo humano, y tantas cosas más... Apunto algo diferente: creo que la principal razón por la cual nos sublevamos contra la guerra es que no podemos hacer otra cosa. Somos pacifistas porque nos vemos precisados a serlo por razones orgánicas (1979, t. XXII, p. 197).

"Esto no se comprende claro está sin explicación", agrega en párrafo a continuación. Opino lo siguiente: desde épocas inmemoriales se desenvuelve en la humanidad el proceso del desarrollo de la cultura (sé que otros prefieren llamarla "civilización"). A este proceso debemos lo mejor que hemos llegado a ser y una buena parte de aquello a causa de lo cual penamos... Las alteraciones psíquicas sobrevenidas con el proceso cultural son llamativas e indubitables. Consisten en un progresivo desplazamiento de las metas pulsionales y en una limitación de las mociones pulsionales. Las sensaciones placenteras para nuestros ancestros se han vuelto para nosotros indiferentes o aun insoportables. El cambio de nuestros reclamos ideales éticos y estéticos reconoce fundamentos orgánicos.

Entre los caracteres psicológicos de la cultura, dos parecen los más importantes: el fortalecimiento del intelecto, que empieza a gobernar a la vida pulsional y la interiorización de la inclinación a agredir, con todas sus consecuencias ventajosas y peligrosas. Ahora bien, la guerra contradice de la manera más flagrante las actitudes psíquicas que nos impone el proceso cultural, y por eso "nos vemos precisados a sublevarnos contra ellas, lisa y llanamente no la soportamos más" (1979, t. XXII, pp. 197-198).

Dos temas había retomado Freud de su visión de la guerra formulados en el escrito sobre guerra y 
muerte de 1915. Lo que ha provocado su desilusión por el desenlace de esta guerra son:

La ínfima eticidad demostrada hacia el exterior por los Estados que hacia el interior se habían presentado como guardianes de las normas éticas, y la brutalidad en la conducta de los individuos, quienes por su condición de partícipes en la más elevada cultura humana, no se los había creído capaces de algo semejante (1979, t. XIV, p. 282).

Esta lúcida anticipación a la teoría de las pulsiones y a su ambivalencia ante la ley ha refutado la existencia de su maldad intrínseca:

En sí, estas mociones pulsionales no son buenas ni malas. Las clasificamos así, a ellas y a sus exteriorizaciones, de acuerdo con la relación que mantengan con las necesidades y las exigencias de la comunidad humana. Ha de concederse que todas las mociones que la sociedad proscribe por malas - escojamos como representaciones las mociones egoístas y las cruelesse cuentan entre estas primitivas" (1979, t. XIV, p. 283).

Líneas más abajo, Freud retomará su expresión de "ambivalencia de los sentimientos" como la mezcla característica de esas pulsiones que había investigado desde Tótem $y$ tabú. Amor y odio aparecían juntas frente al padre primitivo, $y$ ahora
Freud los llama destinos de la pulsión presentes en el carácter del hombre que pueden tomar como objeto a una misma persona.

Sólo después de superados tales destinos de pulsión se perfila lo que se llama el carácter de un hombre, que, según es notorio, únicamente de manera harto defectuosa puede clasificarse como "bueno" o "malo". El hombre rara vez es íntegramente bueno o malo: casi siempre es "bueno" en esta relación, "malo" en aquella otra, o "bueno" bajo ciertas condiciones exteriores, y bajo otras, decididamente "malo" (1979, t. XIV, p. 283).

Así como las pulsiones no son buenas o malas en sí mismas, tampoco puede predicarse una aptitud para la cultura absolutamente egoísta o altruista, esto es, que lo humano tienda a vínculos de disociación o de asociación por naturaleza. Los hombres no poseen una tendencia natural a la sociedad como tampoco son insociables de por sí. Participan de ambas tendencias, y su modo de exteriorizarse depende del uso social en cada comunidad. Ninguna tendencia humana escapa a su forma pulsional primitiva ambivalente ante la cultura o la ley paterna desde el primitivo totemismo: tampoco todas esas capas psíquicas olvidan huellas desde el animismo y la magia primera: 
Todo estadio evolutivo anterior se conserva junto a los más tardíos devenidos a partir de él: la sucesión envuelve a la vez una coexistencia, y ello a pesar de que los materiales en que transcurre toda la serie de transformaciones son los mismos (1979, t. XIV, p. 287).

Esta plasticidad asombrosa de las pulsiones es la que permite a Freud encontrar la capacidad de involución o lo que él mismo denominara como "regresión". Los estadios primitivos pueden restablecerse siempre; lo anímico primitivo es imperecedero. El sueño, agrega a continuación, es la prueba más fehaciente de la existencia de esta regresión en toda la vida afectiva:

Sólo el sueño puede dar testimonio de la regresión de nuestra vida afectiva a una de las etapas del desarrollo más tempranas. Digno de notarse es, por ejemplo, que todos nuestros sueños están gobernados por motivos puramente egoístas (1979, t. XIV, p. 287).

\section{Propuesta de Hobbes: de estado de necesidad a necesidad de estado}

A Hobbes le corresponde ser precursor de la versión de la guerra como un estado de naturaleza o necesidad -latente en todo hombre- en la lucha universal del reconocimiento de todos contra todos: "Todo hombre es un lobo para el hombre". Ese honor lo concede Freud al verlo como pionero en la misma Interpretación de los sueños. En el capítulo VI de ese libro maravilloso, que revolucionó todo el continente de las ciencias humanas, el autor de esta interpretación de lo onírico había dado ese crédito a Hobbes al considerarlo visionario del sueño puesto como regresión al proceso primario de lo psíquico, o retorno del proceso primordial de lo humano, el inverso de nuestras imaginaciones de la vigilia, pues "cuando estamos despiertos el movimiento comienza en uno de los extremos, y cuando dormimos, en el otro" (Freud, 1979, t. V, p. 536). Al parafrasear su texto, se diría que los hombres deshacen en la noche lo que hacen durante el día, pues allí donde empieza el sueño se da como el término o culminación de la vigilia. Mientras la concepción diurna va de lo sensible al concepto, pasando por la imagen, en cambio el sueño empieza donde la conciencia diurna termina, y esos restos que se invertían antes en la acción motora de la percepción a la conciencia ahora se devuelven de la conciencia a la percepción e invisten o cargan 
de nuevo las dormidas huellas del pasado, que van a tener un nuevo orden, ya no como el orden diurno de concebir algo para poder actuar sino que desde la inacción máxima del sueño - lo más parecido a la muerte- los hombres devuelven toda su historia individual y colectiva para retornar a ser contemporáneas del animismo, de la magia, de la religión, del fetichismo, de la omnipotencia del pensamiento primitivo.

Dicha cita que hace Freud en la nota 12 del capítulo VI de la Interpretación de los sueños sirve para empalmar el aporte de Hobbes a lo que se puede llamar el paso analítico de la naturaleza a la cultura, cuyo experimento intenta mostrar cómo sería el hombre si se dejase al libre juego de sus pasiones. Qué o cómo sería el hombre sin ninguna ley, sin ningún orden, sin ninguna regla o norma legal, es decir qué sería lo real humano, libre de todo orden simbólico o puesto a merced de su fuerza impulsora básica: el apetito. Y el apetito lo define Hobbes al empezar el Leviatán: "Cuando el conato está dirigido hacia algo que lo causa es llamado apetito o deseo". Y añade en párrafo siguiente:
Lo que los hombres desean se dice también que lo aman y se dice que odian aquello por lo cual sienten aversión. De modo que el deseo y el amor son lo mismo, con la excepción de que cuando decimos deseo, ello significa que el objeto está ausente; y cuando decimos amor, que en la gran mayoría de los casos, está presente. Asimismo, por aversión damos a entender la ausencia, $y$, por odio, la presencia del objeto (1994, p. 50).

El único animal, cuyos deseos se continúan unos a otros como una suma que se sucede en un proceso que solo termina cuando la cosa es realizada o dejada por imposible, es el hombre, y a esto lo llama Hobbes el proceso de la deliberación. "Se dice, pues, que una deliberación termina cuando aquello sobre lo que estábamos deliberando es hecho, o es juzgado imposible". Y enseguida concluye: "En la deliberación el último apetito o aversión que procede inmediatamente es lo que llamamos voluntad, el acto, no la facultad de querer... Por lo tanto, voluntad es el último apetito de la deliberación" (1994, pp. 56-57). Voluntad o deseo que solo cesa con la muerte y, por lo tanto, la satisfacción de las necesidades humanas nunca se pueden mirar como conquistas definitivas ni como éxito continuo, 
[...] porque mientras vivamos aquí no habrá tal cosa como una perpetua tranquilidad de ánimo... ya que la vida misma es movimiento, y jamás podremos estar libres ni de deseo ni de miedo, lo mismo que tampoco podremos estar libres de sentido (1994, p. 58).

Así pues, el primer filósofo que entendió ese rastro siniestro en el hombre se llama Tomas Hobbes, porque para poder demostrar que el hombre no es un animal sociable, ni político, ni es un animal - como diría Aristóteles - hecho para la vida buena, sino que, por el contrario, el hombre es una insociable sociabilidad cuyo apetito es el de volver siempre a recorrer su estado original al intentar retornar a sus estados presociales como su estado de naturaleza. Ese animal es un híbrido porque es sociable e insociable a la vez, porque se asocia no por libertad sino por necesidad y porque necesita de la fuerza para llegar a hacer un pacto. Y Hobbes demuestra que el deseo de los hombres en estado de naturaleza lleva a la muerte, porque el deseo es omnipotente en cuanto quiere siempre apoderarse de lo que los demás desean, y el límite que tiene la naturaleza es que crea entre los hombres rivales como semejantes, por cuanto apetecen en la medida en que el otro apetece lo mismo y solo apetecen cuando ven amenazado el objeto que apetecen, y por lo tanto - dice Hobbes - es ese el estado de naturaleza donde prima el derecho natural: nada es mío, nada es tuyo, nada es de nosotros porque ninguna posesión ni ningún apoderamiento de objeto puede durar en cuanto todos son capaces de apoderarse de lo mismo y, por lo tanto, el derecho natural lleva a la guerra de todos contra todos, porque si todos quieren lo mismo, nada es de nadie ni posible de conservar. $Y$ en ese sentido, Hobbes dice que el instinto de conservación, que es el instinto fundamental de los hombres, ese instinto es el único que puede salvar de la autodestrucción, puesto que permite avizorar una ley natural en la que los hombres se den cuenta de que la amenaza del estado de naturaleza lleva a la desconfianza universal, a la envidia de todos contra todos y a la competencia a muerte entre la vanidad en lucha por el poder.

El estado de naturaleza solo sirve para salir de ella lo más pronto. Por lo tanto, Hobbes anticipa que el deseo de poder es insaciable y que, dejado a su solo juego de fuerzas, ese deseo real suyo lleva a lo que podríamos llamar una amenaza 
permanente, porque la guerra no consiste solamente - como la lluvia-, en que haya en este momento lluvia, sino en que amague con llover. En síntesis, Hobbes asegura que el estado de naturaleza permanece latente $y$, por tanto, disocia a los hombres pero también los conmina a salir de ese estado porque las mismas pasiones conducentes a la guerra -la competencia, la desconfianza, la vanidad- están presentes como pasiones hacia la guerra tanto como pueden emerger hacia la búsqueda de una salida de ese estado. Lo único bueno de ese estado de naturaleza es que su propia dinámica autocontradictoria obliga a los hombres a huir de ese estado. El secreto está en que, al desarrollar estas mismas pasiones por la muerte, exacerba el miedo a morir de manera violenta en ese estado de desconfianza, incertidumbre e inseguridad general creada.

El temor a la muerte, el deseo de una vida cómoda y la esperanza de lograrla mediante el trabajo inclinan a los hombres a buscar la paz o el cese de hostilidades permanentes. Es la misma angustia ante la muerte la que obliga a emerger la razón, la cual actuando junto con esas pasiones - temor, deseo y esperanza- sugieren reglas, llamadas leyes naturale,s para vivir pacíficamente en común.

Hemos visto hasta aquí cómo las mismas pasiones que incitan a la guerra pueden ser reorientadas por la razón o el cálculo para salir de ese estado contradictorio no solo en sentido lógico sino ontológicamente. Puesto que las mismas tres grandes causas de enemistad entre los hombres - temor, deseo y esperanza- pueden unirse para neutralizar esa pasión imaginaria -el deseo de reconocimiento-, llamado egoísmo o vanagloria, por otros, cuya omnipotencia únicamente puede ser reorientada por el cálculo racional para avizorar hacia un estado de conservación superior que obligue a los hombres a pactar, esto es, a romper el círculo siniestro de la guerra de todos contra todos. Así pues, la tarea de la razón consiste en inventar medios que permitan hacer prevalecer ese miedo a la muerte y ese deseo de una vida cómoda y laboriosa, de tal manera que se sobrepongan o anulen los deseos autodestructivos de orgullo o vanagloria.

Ese último Lobo, llamado el Leviatán, aparece como un lobo más fuerte que los demás lobos, puesto que es el representante de todas 
esas fuerzas naturales o de las fuerzas de conservación, pues obliga a la conciencia emergente a arriesgar su vida a cambio de obtener su reconocimiento por un poder superior que los proteja. Y en ese sentido, Hobbes anticipa lo que Hegel va a llamar "la dialéctica del amo y del esclavo". Quiere decir el filósofo que el hombre, para poder ser libre, necesita exponer su vida para ser reconocida como libre por otra conciencia temerosa de morir, pues solo venciendo el miedo a morir se descubre que hay un imperativo más fuerte que la pasión, llamado cálculo racional de las pasiones, único modo que permite a los hombres acceder a un principio de realidad capaz de aplazar el principio de placer por un rodeo. El principio de placer conduce al principio de realidad, cuando anticipa un necesario pacto simbólico regulador del principio del placer o de la búsqueda repetida de la pasión por saciar su goce de la cosa que conduce a la muerte. La única forma para Hobbes de salir del estado de naturaleza y su derecho natural es mediante la ruptura del apetito de goce total o uso de la razón, que llega a la conclusión de que no vale la pena agotarse en puro placer del estado de naturaleza con derecho natural omnímodo, pues el deseo de vivir abandona su libertad absoluta egoísta por necesidad de prolongarse con otros.

La paz es el triunfo del derecho a la vida y el derecho a la vida tiene forma lograda cuando los hombres elevan sus máximas racionales a la existencia de un poder soberano común. El cálculo no es más una anticipación de un orden que permita regular sus pasiones futuras, $y$ desde que los hombres calculan empiezan a pensar, pues ante su angustia por un futuro incierto o la de volver al pasado mortífero, solo queda la opción del presente ordenado por el cálculo. De allí nace su noción de tiempo entre los hombres, pues ellos no tendrían tiempo ni orden simbólico, o reglas y normas, ni la posibilidad de vivir, si no establecen un cálculo racional de sus pasiones. Hobbes sabía que el temor mutuo entre los hombres no desaparecía por una ley natural y el ciclo de la venganza retornaba si no se reemplazaba el temor difuso ante todos los lobos por uno determinado ante un último lobo, el soberano. Hobbes llegó a pensar que la sola ley natural, sin acompañamiento de la ley civil, tampoco serviría y que, por lo tanto, no valen los teoremas que la razón 
sin el concurso de una espada que no solo tenga poder de disuasión de la guerra, sino que garantice el derecho a la paz mediante el monopolio de la violencia, llamada ahora violencia legítima o potestas. Surge la auctoritas, cuando los autores delegan sus derechos de autor en una personal legítima que los representa a todos. Este es el lema fundamental: "es la autoridad, no la verdad, la que hace la ley".

Por lo tanto, Hobbes resuelve la condición siniestra del estado de naturaleza en la existencia de un último lobo: el soberano, que no es más que el definidor de las reglas para que los hombres puedan ejercer sus pasiones. No quiere decir que los hombres abandonen sus pasiones, jamás lo podrán hacer, porque sería como abandonar lo que los caracteriza, el deseo de conservarse y de aumentar su poder; no, los hombres son voluntad de poder, los hombres son fuerza de poder, pero esos deseos individuales naturales no se podían ejercer pues se destruían a sí mismos, porque muchos hombres apetecen al mismo tiempo la misma cosa. Los hombres necesitaban renunciar a su derecho de autoprotección a cambio de la protección de ese dios mortal, el Leviatán: “[...] único cuerpo político o sociedad civil que puede ser definido como una multitud de hombres, unidos como una sola persona por un poder común, para su tranquilidad, defensa y beneficio comunes". Para continuar la guerra, pero por otros medios, con reglas, con normas, se define el Estado, que no es más que un sistema de normas que regula la violencia; pero la violencia monopolizada, una violencia legítima, pues establece el derecho o el Estado de derecho. Poder político concentrado en un solo centro y no en múltiples.

Hobbes, sin embargo, desconfiaba de eso siniestro que en el hombre aparece por primera vez como una bestia que siempre aspira volver al estado de naturaleza, porque el que ha estado, el que ha vivido el ansia de poder jamás lo olvida, y, por lo tanto, el estado de naturaleza es latente y siempre volverá en la medida que el soberano no sea capaz de monopolizar la violencia en un solo poder, en un solo centro legítimo. En conclusión, Hobbes descree de la felicidad en esta vida como si hubiera un fin último distinto al deseo:

La felicidad de esta vida, concluye el Leviatán, no consiste en el reposo de un espíritu satisfecho, ya que no hay tal fin último $[\ldots]$ ni 
un soberano bien. La felicidad es el avance continuo del deseo de uno a otro objeto, en el cual el logro del primero no es todavía más que el camino hacia el segundo. La causa de esto es que el deseo del hombre no tiene por objeto disfrutar una sola vez, y durante un solo instante del tiempo, sino asegurar el camino de su deseo futuro [...] no puede asegurar el poder $y$ medios para vivir bien, que tiene presentes, sin adquirir más... (1994, pp. 63-64).

Hobbes anticipa esa lucha a muerte por el reconocimiento. Hegel demuestra que solamente el que mira a los ojos a la muerte y no teme vencerla, ese es capaz de ser libre; esclavo es el que no resiste la mirada del otro porque teme verla en los ojos del otro. Quien resiste la mirada del otro es capaz de soportarla, libera su conciencia. El que teme ver la muerte en los ojos ajenos, esa es una conciencia servil. Tal como recuerda esa dialéctica hegeliana de la lucha a muerte entre las conciencias, el esclavo se calla su pasión pero nunca la olvida y el aprendizaje de la cultura a través del trabajo, el lenguaje y la comunicación son para el esclavo la venganza eterna del amo, porque el único que sabe trabajar, el único que sabe elaborar el producto de su goce, el único que socializa es el que acepta el ser-para-otro y el que accede a la conciencia mediante el temor mortal del otro. El amo, valido de su prepotencia, entrega el usufructo de la cosa, ignora el modo de uso del instrumento de trabajo y se atiene a que el otro le produzca la cosa y al producirse esa cosa olvida lo que es el trabajo, el lenguaje, la interacción humana, y, por lo tanto, el esclavo, a través del aprendizaje de la cosa, de cómo se elabora, asimila la cultura o la formación del carácter; formarse a sí mismo, elaborar su carácter es elaborar su destino; y de ahí arranca Freud.

\section{¿Es funesto el destino pasional humano según el psicoanálisis?}

Freud parte de este supuesto: "La anatomía del hombre es su destino". Esto en el fondo ha sido traducido por sus sucesores con la frase: "La anatomía del hombre es su carácter". Esto quiere decir que el animal humano, a diferencia de los demás animales, no tiene naturaleza fija sino que la construye como carácter ético. Y cada destino se labra su suerte como un animal que se autoproduce tanto en el trabajo, en el lenguaje como en la interacción ética con el otro. El animal humano es el único animal ético: animal de costumbres, lo llamaba Aristóteles, 
o animal cuyo caldo de cultivo es su ethos o la segunda naturaleza que se agrega a sus instintos mediante los hábitos, costumbres o formas de vida culturales. Los demás animales no conocen ni aprenden de las costumbres, los hábitos ni las reglas, tampoco manejan ninguna manera cultural ni cultual de habitar el mundo, pues no tienen que construir su morada ni modelar hábitos desde comer hasta caminar. Puesto que el animal humano es el único animal que nace desvalido, abandonado, abyecto o tirado al mundo, tiene que aprender todas las operaciones de su cuerpo, desde incorporarse y caminar hasta gozar del tacto y el gusto, e incluso sentir capacidad amatoria como derivado sentido espiritual donde se incluye al otro. Entonces los sentidos del hombre son construidos por imitación cultural en el puro devenir humano, contrario a la vida animal que no tiene historia: se puede construir la historia del ojo, el oído, el tacto y el gusto tanto como la historia del amor. El instinto animal es el mismo secularmente, mientras el del humano es plástico y cambiante.

Hegel y su discípulo Marx dirán que es primero el reconocimiento que el conocimiento, y desde los juveniles Manuscritos económico-filosóficos, Marx diría que el hombre se produce o autoproduce en todos sus sentidos, en ese metabolismo con la naturaleza e incluso en sus sentidos erótico-amatorios. De manera que el hambre humana no es hambre de cualquier cosa ni el amor humano es amor a cualquier objeto. Las necesidades han de interpretarse, pues el cuerpo humano no se porta o soporta como si lo arrastrara como algo externo; el cuerpo humano no se porta como algo dado y fijo sino que el hombre tiene que llegar a habitarlo, a apropiarlo hasta llegar a ser lo que ya se es o a hacerlo suyo como un habitáculo propio. De allí que se necesite representárselo en esquemas mentales y diseñarlo en sus redes al modo de aparato neuronal. Esto es lo que hace que el cuerpo se vuelva una representación o un símbolo. Y es Freud quien desprende al humano de ese primitivo estado natural de sensaciones brutas para mostrar que es en el estado cultural donde ese único animal aprende o aprehende del Otro todas las motivaciones morales, religiosas, éticas, jurídicas, artísticas; ellas provienen de que nació en estado de invalidez y de que sus primeros meses son de postración o 
dependencia total frente a Otro llamado el prójimo -el próximo que soporta su cuerpo prematuro y le presta su imagen para que la incorpore o la internalice hasta dotarlo de forma humana-. El más próximo a mí, el que me soporta, el que es capaz de alimentar e interpretar todas mis demandas, el que no me deja caer y el que me amamanta, ese que me presta figura humana y el primero que me presta la forma de hacerme hombre. Porque como hemos dicho, para el psicoanálisis el cuerpo humano nace fragmentado como una masa especie inorgánica, amorfa como una cantidad o reserva de energía o un depósito de órganos sin forma.

El neonato no tiene la posibilidad de seguir la mirada del otro, no es capaz de fijar en un objeto su mirada, tiene que esperar al noveno mes para que por primera vez, en compañía de otro, sea capaz de reír, cuando siente al otro reconociendo al tiempo lo mismo que él ve.

Freud hace un experimento con un niño - que es su sobrinoquien a los 18 meses por primera vez pronuncia un fonema. En ese experimento Freud ve el anticipo de lo que va a ser el núcleo de su teoría: la pulsión de muerte. Los hombres, como ese niño, nacen desadaptados del medio o, al menos, no son coadaptados como el animal a él. Nuestro cuerpo no tiene sed ni hambre de cualquier objeto, sino que aprende a interpretar esas operaciones a través del otro que interpreta sus necesidades de comer, beber, e incluso dormir. Un niño ni siquiera sabe reconocer en el cuerpo la localización exacta del órgano de su dolor, no puede nombrar el órgano que padece pues nada más terrible de ver que un niño que cuando va a señalar sobre lo que le duele no sabe indicar verbalmente como tal el órgano, de modo que lo más terrible del dolor humano es no poder nombrarlo. El sufrimiento más impotente es ignorar el objeto correspondiente al que siente en el inicial cuerpo fragmentado.

Freud anticipó la pulsión de muerte a través de ver a ese desvalido, que a los 18 meses pronunciaba solamente dos fonemas: "a", cuando aparecía la madre y "o", cuando la madre se fugaba. Freud creyó ver en esos dos fonemas el origen de toda el habla, y atribuyó el fonema "o" pronunciado a la fuga y el "a" con júbilo a la vuelta del objeto perdido. Él tiraba un carrete cuando la madre se iba y lo volvía a recoger a su cuna 
cuando ella volvía; pero Freud creyó que ese fonema "o" significaba Fort 'fuera' y "a”, $D a$ 'acá. $Y$ ese juego de la bobina lo hacía el niño de tal manera que podía con ese solo fonema, con esa dupla, manejar la ausencia y la presencia de la madre. Es un juego más del Fort que del $D a$, pues es obvio que el júbilo está en el $D a$, pero la furia, la capacidad de fuera e incluso de echar a la madre se llama el Fort. Y en ese juego, dice Freud, el símbolo le permite al niño, bajo esa bobina, soportar la ausencia y la ruptura de todo ese espacio vacío donde se fuga la madre, y la representación de todo otro objeto que se pueda perder allí tiene que pasar por ese mismo abandono; es decir, los símbolos son la única manera de regular la frustración del abandono, no hay otra manera de hacer el duelo para el humano.

El humano aprende a hablar porque es su único modo de mantener retenido el dolor y contenido en sí mismo. El dolor solo se vence a través del lenguaje y solamente el que habla puede vencer el dolor; pero Freud muestra que esa imagen de la madre en el símbolo se llama el representante de una representación, lo que él está representándose es la fuga, la huida, el abandono; por lo tanto, el símbolo mata la cosa, pero en el momento en que la mata, también la vuelve eterna, porque desde ese momento el símbolo nunca desaparecerá y en ese instante el niño toma distancia de la madre y puede incorporarla ya no físicamente sino mentalmente. Por primera vez se es hombre cuando se tiene lenguaje; antes el hombre no puede tener ningún valimiento propio, y la lengua es la condición de salir del estado abandonado de un ser prematuramente nacido. Por ser nosotros seres absolutamente prematuros, nacidos antes de tiempo, estamos sometidos al influjo permanente de los símbolos y las imágenes; somos deseantes porque fuimos deseados por otro cuyo proyecto nos nombró; no tenemos sino un nombre por el proyecto o la ilusión de otro y, por lo tanto, estamos metidos dentro de un orden que se llama la cultura, producto del deseo que otro tuvo de nosotros. Los niños autistas no tienen imagen de sí mismos porque nunca fueron deseados, sufren de muerte azul - y aún hoy se mueren prematuramente y mueren azulados-. Esos niños autistas no podrán recuperarse, no podrán jamás acceder a un símbolo porque no tuvieron jamás una imagen de su 
cuerpo ni fueron capaces de identificarse con un espejo. Somos el único animal que se puede identificar en un espejo... Y no solamente se reconoce como un cuerpo, sino que ya tiene una primera forma de diferenciar entre su cuerpo y lo que no es su cuerpo merced a una imagen de esa primera forma que introduce a los hombres, lo que se llama: la pulsión de muerte.

La presencia de la muerte en el lenguaje aparece primero en la captura que las imágenes y los símbolos producen en el humano merced a su condición desvalida originaria y originante que permita al hombre superar su desvalimiento cuando el cuerpo se denomina como un mapa trazado o escrito y atravesado por símbolos e imágenes. Por lo tanto, lo siniestro viene de esa extrañeza ante lo más familiar e íntimo de haber nacido abandonado o en estado de prematuración como una masa de nervios, músculos y tejidos puestos como una cantidad energética sin elaborar. Los símbolos o el proceso de la simbolización provoca una separación de las cosas y una alienación en el lenguaje: la palabra que nombra mata la cosa pero al mismo tiempo la eterniza.

\section{El ominoso paso de la muerte de la imagen a la imagen de la muerte}

El sentimiento de la muerte como intento de transgresión de todo orden y sentido nos ha descubierto el parentesco de ese sentimiento con la tragedia griega y el destino siniestro de sus héroes como Edipo y Prometeo, capaces de desafiar a los dioses y a su destino mortal con el fin de desentrañar los secretos de la naturaleza. Lo ominoso parece proceder de este impulso transgresor de toda ley de la cultura. La pesquisa del psicoanálisis avanza un trecho más hasta desembocar en el origen de ese sentimiento ominoso en la ruptura misma del tabú - la primera norma moral entre los humanos-. Freud deriva ese sentimiento ominoso de una expresión encontrada en uno de sus pacientes: la omnipotencia del pensamiento.

En una nota perdida de Tótem y tabú, el fundador del psicoanálisis dice:

Parece que conferimos el carácter de lo "ominoso" a las impresiones que corroborarían la omnipotencia de los pensamientos y el modo de pensar animista en general, en tanto que en nuestro juicio ya nos hemos extrañado de ambas creencias (Freud, 1976, t. XXIII, pp. 89-90). 
Esta omnipotencia del pensamiento presente en los procesos neuróticos de los obsesivos es un relicto de esa primera visión animista que como hemos mencionado es la primera teoría completa sobre el universo enunciada por el primitivo en su voluntad de apoderarse de la naturaleza y sus secretos. El animismo y su omnipotencia del pensamiento no solo están presentes en las tendencias obsesivas del neurótico para controlar el curso de sus deseos, sino que como Freud mismo analiza en este precioso texto ahora citado pervive en la tendencia de los artistas a crear un mundo imaginario, como en el sueño.

Sólo en un ámbito, escribe, el del arte, se ha conservado la "omnipotencia de los pensamientos", también en nuestra cultura; únicamente en él sucede que un hombre devorado por sus deseos proceda a crear algo semejante a la satisfacción de esos deseos, y que ese jugar provoque - merced a la ilusión artística- unos afectos como si fuera algo real y objetivo (1976, t. XXIII, pp. 93-94).

Esa omnipotencia del pensamiento - matriz de lo ominosoes un relicto de nuestra imaginación estética y nuestro sueño, pero fue en tiempos pasados una acción efectiva del primitivo. De allí deriva el psicoanalista su hipótesis de que en el “comienzo fue la acción".

El pensamiento era verdaderamente acción para el primitivo y sus deseos estaban expresos en sus imágenes. Mito y tragedia, como hemos visto a través de sus héroes arquetípicos de Edipo y Prometeo, encarnaban esos deseos de transgresión y, por eso, fueron vistos como ominosos.

Tenemos fundamento -dice Freud- para atribuirles una extraordinaria sobrestimación de sus actos psíquicos, como un fenómeno parcial de su organización narcisista. Según esto, los meros impulsos de hostilidad hacia el padre, la existencia del deseo de darle muerte y devorarlo, pudieron haber bastado para producir aquella creación moral que creó el totemismo y el tabú.

Si para el primitivo, como afirma el autor, deseos e impulsos poseen el pleno valor de hechos, entonces hay que adjudicarles a sus mitos el valor de obras y considerar que esas tendencias que, en nosotros solo parecen imaginaciones o ficciones, para ellos fueron vividas como acciones efectivamente llevadas a cabo. De allí que la magia, el fetichismo y el animismo fueron no 
solo sus creencias estéticas, éticas y religiosas, sino que adquirieron el carácter de su cosmovisión mítica y su ritual, esto es, formaron su mundo en sus prácticas legítimas y legitimadoras. Ese es el sentido del mito de Tótem y tabú como fantasía real de la humanidad que adquiere estatuto de acto fundador de la comunidad primitiva.

Siguiendo esta idea del mito y la tragedia como actos efectivos donde las imágenes y los símbolos adquieren el carácter de lo real, Freud esboza la hipótesis de un crimen primordial presente en todos los héroes trágicos quienes cargan con la culpa trágica - como Edipo y Prometeo- de haber realizado esos deseos transgresores de rebelarse contra la autoridad divina o humana, y haberle dado muerte. La comunidad atribuye a sus héroes esa culpa de haber efectuado los deseos que ellos han efectuado a través suyo:

El crimen que sobre él se descarga, la revuelta y la arrogancia sobre una gran autoridad, es justamente el que en la realidad efectiva pesa sobre los miembros del coro, la banda de hermanos. Así el héroe trágico - todavía contra su voluntad- es convertido en el redentor del coro (Freud, 1976, t. XXIII, p. 157).
Hemos llegado así al núcleo de la hipótesis de Freud sobre el parricidio como origen de toda cultura humana. La imagen de la muerte deviene muerte de la imagen. Lo siniestro de este funesto destino de lo humano consiste en que la omnipotencia del pensamiento se convirtió en omnipotencia del deseo y debió haber pasado al acto de realizar míticamente el crimen primordial. La violencia de los deseos humanos ha debido conducir el destino de esas pulsiones primitivas a la realización, imaginaria o real de ese crimen que se repite en todos los héroes como transgresión de las leyes humanas. Ese es el estado de naturaleza para el psicoanálisis; la tendencia a repetir ese crimen primordial - ahora de manera simbólica en nuestros deseos reprimidos-de matar al padre y violar sus secretos a través de la posesión de su secreto deseo mejor guardado: la posesión de las mujeres y de la mujer por excelencia que es la madre.

Basta resumir lo esencial del mito parricida narrado en Tótem y tabú:

En un tiempo primitivo, los hombres vivían en pequeñas hordas, cada una de ellas sometida al poder despótico de un macho que se 
apropiaba de las hembras. Un día, los hijos de la tribu, en rebelión contra el padre, pusieron fin al reino de la horda salvaje. En un acto de violencia colectiva, mataron al padre y comieron de su cadáver. Pero después del asesinato se arrepintieron, renegaron del crimen y crearon un nuevo orden social, instaurando simultáneamente la exogamia (o renuncia a la posesión de las mujeres del clan del tótem) y el totemismo, basado en prohibir el asesinato del sustituto del padre (el tótem). Totemismo, exogamia, prohibición del incesto, tal había sido el modelo común de todas las religiones y en particular del totemismo (Roudinesco y Plon, 2006, p. 1068).

Desde esta perspectiva, el mito del origen del parricidio o la violencia primordial no es más que una extrapolación del llamado complejo de Edipo a un padre primordial, ante cuya presencia u omnipotencia se realiza el crimen fundador de la cultura y la salida del estado de naturaleza. Esa tendencia a repetir ese crimen - presente ahora en los fantasmas del hombre civilizadose efectuó realmente en un acto de transgresión de esas dos prohibiciones o deseos reprimidos de la humanidad contenidos en los dos tabúes propios del totemismo: la prohibición del incesto y la de matar al padre-tótem. La omnipotencia de un padre original de la horda por encima de toda ley dio origen a un crimen que, al cometer esa doble transgresión, la convirtió en ley de la cultura, origen de todos los sentimientos ambivalentes ante ese representante de sus prohibiciones: el padre muerto ahora eternizado en los sentimientos inconscientes de los neuróticos, o sea, los actuales enfermos de la cultura.

Este es, pues, el drama y la trama vivida a través de las peripecias que la cultura impone al deseo. El deseo se mueve en esta ambigua relación con la ley cultural sustentada en ambas prohibiciones. Pero estas prohibiciones solo hablan y reproducen esas tendencias primordiales del deseo. En el fondo, esta ley de la cultura transmite la discontinuidad con el estado de naturaleza acariciado como un goce primordial. El deseo existe porque existe ese Otro de la cultura que nos separa de esos estados primordiales del estado de naturaleza.

Pero esas prohibiciones solo pudieron tener tal fuerza original porque persisten en el imaginario de los hombres como las pulsiones primordiales. Querer volver al estado de naturaleza no es más que un estado mítico solo presente como alucinación de un estado sin ninguna de esas 
prohibiciones. Lo que para el primitivo era una fuerza viva que intentó pasar al acto o realizar en la acción, para el hombre de la cultura no es más que una pulsión fantaseada que debe sofocar a medida que crecen los preceptos de la civilización.

Freud ha descubierto la fuente de lo ominoso en la supervivencia de esa omnipotencia del pensamiento que pretende llegar a poseer la cosa misma más allá de cualquier principio de placer permitido por la cultura. El ser humano es el único animal ambivalente en sus pulsiones ante la ley que rige su deseo. Su deseo regido por el deseo del Otro anhela, sin embargo, regresar a una morada ideal de la cual ha sido alienado, pero que siente como lo más íntimo. Nada más exíntimo que eso alucinado como lo más íntimo, nada más cercano o familiar que ese lejano paraíso del cual desde siempre ha sido expulsado. Y, por lo tanto, lo siniestro en el hombre consiste en que este quiere regresar siempre a violar todo lo que ha construido como cultura; el hombre es el único animal que ama, más que el orden, ese desorden o caos del cual procede toda su fantasía. La vuelta al caos, la destrucción de su propio cuerpo y de todo cuerpo construido, ese es el nombre de la pulsión de muerte. Y, por lo tanto, Freud piensa que en todo hombre hay una pulsión homicida y suicida, pues ante todo late en él ese sentimiento de volver a violar, de transgredir todas las leyes que ha construido en su modo de habitar la Tierra. Y en eso consiste la diferencia con los demás animales. El animal humano no solamente construye una morada, sino que siempre permanece ajeno a ella, pues el deseo de transgresión nace al tiempo con la prohibición de su anhelo alucinado.

Esta ruptura de todo orden cultural o simbólico fue anunciada por todos los filósofos de la tragedia griega. Basta nombrar el comentario de Nietzsche -el otro filósofo que anticipa a Freud-quien muestra en el capítulo IX del Nacimiento de la tragedia ese mismo impulso de Edipo y Prometeo. Nietzsche al hablar del destino trágico de todo héroe dionisíaco- dice que Edipo es aquel que "hace tal vez a causa de su obrar que perezcan toda ley, todo orden natural, incluso el mundo moral". Y se pregunta Nietzsche:

[...] pues ¿cómo se podría obligar a la naturaleza a entregar todos sus secretos a no ser oponiéndole una resistencia victoriosa, es 
decir, mediante lo innatural? Este es el conocimiento que yo veo expresado en aquella maravillosa trinidad de destinos de Edipo: el mismo que soluciona los enigmas de la naturaleza - de aquella esfinge biforme-, tiene que transgredir también como asesino de su padre y esposo de su madre, los órdenes más sagrados de la naturaleza. Más aún el mito parece querer susurrarnos que la sabiduría, y precisamente la sabiduría dionisíaca, es una atrocidad contra la naturaleza, que quien con su saber precipita a la naturaleza en el abismo de la aniquilación, ése tiene que experimentar en sí mismo la disolución de la naturaleza (Nietzsche, 1871, p. 94).

Edipo los quiere profanar sin saber el destino trágico que le espera. $\mathrm{Al}$ inquirir sin descanso, ignora que él es el mismo investigado. Edipo es un santo inocente, porque igual que Prometeo comete un robo hecho a la naturaleza divina mediante el sacrilegio, conquista la humanidad, las cosas óptimas y supremas de que ella puede participar y tiene que aceptar por tanto sus consecuencias (Nietzsche, 1871 , p. 96).

\section{Una primera hipótesis sobre la existencia de una violencia primordial}

El complejo de Edipo no es más que la manera como el hombre debe abandonar el estado prematuro, el estado de invalidez o el estado de dependencia de la madre para poder encontrar un significado a través de la imagen de la madre y el nombre del padre. Por lo tanto, todo lo que se llama siniestro en el hombre no es más que el intento de negarse a abandonar jamás esa posición narcisista primordial que lo lleva a la muerte. Y ese narcicismo primordial lo llama Freud "el narcisismo primario", como el amor al niño que hay dentro de cada uno de nosotros. Como se diría de Leonardo da Vinci, que cuando amaba a los jóvenes efebos de cabelleras blondas, amaba al niño de cabellera blonda que él fue un día. De allí deriva Freud el narcisismo propio de las conductas homosexuales, en la que "ellos se toman a sí mismos como objetos sexuales", o "buscan a hombres jóvenes semejantes a su propia persona, a quienes quieren amar como sus madres los amaron a ellos". Esto quiere decir que aman su propia imagen en otro semejante al que quieren amar de modo semejante a como fueron amados. Leonardo había hecho una idealización de sí mismo y ese Yo ideal era la materia prima de su obra, como se ve en la sonrisa enigmática de la Gioconda o en el cuadro de Santa Ana y el niño. 
$\mathrm{Y}$ todos llevamos esa imagen ambivalente, ambigua o bisexual porque la imagen primordial nos hizo ser primero mujer a todos y atravesar el reflejo de la madre, pues, antes que cualquier otra forma, construimos los objetos de nuestro amor calcados sobre esa imagen narcisística o de reflejo nuestro que es la imagen materna. Terminamos siempre por escoger el objeto de nuestros amores y fantasmas sobre el modelo de la madre.

Pero el yo ideal que fuimos debe ser reconquistado a través de ese ideal del Yo que la cultura paterna nos permite. Sin embargo, debe hacerse el duelo por todo aquello que se debe abandonar de ese yo ideal. Pero esa pérdida siempre retorna, como todo lo reprimido, ya sea en figuras fantaseadas o en proyecciones derivadas, como las fabricadas sobre los hijos, nuestros narcisismos vicariantes: se ama en el hijo lo que se fue o lo que se quiso haber sido hasta el punto de que "su majestad, el bebé" es omnipotente en sus deseos, debido a que sus padres deponen su propio narcisismo a nombre de prolongarse a sí mismos en sus hijos.

Se podría hablar, entonces, de que el narcisismo primario, confirmado por la observación de los niños y también de los pueblos primitivos, se caracteriza en ambos por el uso de la magia y de la llamada omnipotencia del pensamiento. Ese es el núcleo del fenómeno de lo siniestro.

La imposibilidad de abandonar esa imagen primera vuelve al narcisismo, estado normal de la evolución ontogenética y filogenética de la especie. Podríamos decir que esa etapa correspondiente, en el niño, al estadio del espejo, y, en los pueblos primitivos, a su etapa mítica, está signada por el desamparo real, cuya compensación es la omnipotencia del pensamiento..

El cuerpo propio tomado como objeto de sus pulsiones o el cuerpo social primitivo visto como animismo mágico es lo que llamamos una sobrestimación sexual de todas sus operaciones psíquicas hasta el punto de creer que todo lo deseado, por el solo hecho de serlo, ha de convertirse en real. Esta experiencia es la que brinda la idea de completitud o plenitud en la que el sujeto se identifica con la imagen de sí mismo. La magnificación de la imagen de sí mismos, individual y colectiva, puede observarse no solo en los delirios de grandeza de un psicópata individual, sino de una masa artificial, 
cuando se une como multitud en un líder que los identifica y los convierte en masa compacta, sólida y omnipotente.

La visión del narcisismo primario, base de este autoerotismo primitivo de infantes y pueblos, quedaría incompleto si no viéramos cómo el amor de Narciso por sí mismo termina en la muerte. El que quiere besarse a sí mismo en la laguna, como en el mito primitivo, termina ahogado en la laguna. El amor excesivo por sí mismo lleva a la muerte como el narcisismo primario termina en el masoquismo primario. Este enamoramiento de sí mismo o el apasionarse por alguien sin darse cuenta de que es una proyección de sí mismo, ese doble suyo que lo pierde y lo mata, como en el ritual de las tragedias amorosas. El masoquismo se entiende como aquel placer que está ligado al dolor. Se podría decir que hay un masoquismo erógeno desde el momento en que se goza al infringirse dolor o, como en el masoquismo femenino, cuando se asume como castigado, flagelado o victimizado por otro, $y$, finalmente el masoquismo moral, en el que los sujetos no esperan un sufrimiento ocasionado por un compañero, sino que se las arreglan para obtenerlo de distintas circunstancias de la vida. Es lo que se llama comúnmente sentimiento inconsciente de culpa.

Pero Freud indica que el masoquismo primario, al igual que el narcisismo primario, es una manifestación de la pulsión de muerte. Así pues, ser azotado por el padre puede remitir al deseo de tener relaciones pasivas con él. De este modo, el masoquismo, como el narcisismo, revela la existencia del fenómeno del doble. Ambos provienen de la inclinación de todo sujeto a buscar el sentido de su existencia en Otro primordial al que le planteamos la existencia de nuestro ser y que no responde. La mirada del Otro, constitutiva inicial de nuestro ser, se supone siempre como la que sostiene en la existencia y a partir de ahí el sujeto supone lo peor y nunca está seguro de existir ante los ojos del otro cuando sufre.

Ese Otro que se considera lo que falta en sí mismo para obtener una imagen completa o propia de la plenitud propia es lo que se demanda con el objeto de reafirmar o confirmar siquiera que el sujeto existe. Hacerse castigar por el Otro constituye el núcleo de las fantasías masoquistas y perversas, y convertirse en víctima u ofrecerse como objeto 
victimizado por el Otro se convierte no solo en fantasía individual, sino en fantasma de pueblos enteros que se ofrecen a la guerra como materia disponible o carne de cañón.

Ahora estamos en condiciones de reconocer ese sentimiento siniestro en una especie de violencia primordial por parte del Otro, cuya mirada turbadora se necesita para sentirse vivo así sea al precio de un castigo.

El psicoanálisis llama siniestro, ominoso o monstruoso ese sentimiento de malestar sentido ante algo aparecido antes como familiar. La ansiedad de sentirse perdido o extraviado aparece en fenómenos elementales patológicos, como en vivencias de despersonalización o extravío. Lo siniestro sería provocado por la aparición en lo real de algo que se recordaría en lo más íntimo. En su artículo Lo ominoso, Freud se pregunta por las circunstancias desencadenantes.

El artículo gira en torno a la cuestión de la certeza y del tipo de dudas que generan ciertas situaciones del registro de lo fantástico. Varios tipos de límites provocan una inquietante extrañeza en cuanto se los suprime: los límites entre vivos y muertos, entre objetos animados e inanimados, pero también entre sueño $y$ realidad, entre consciente e inconsciente. La confusión de estos límites se enfrenta con la incertidumbre, con lo indecidible, con lo imposible, y ocasiona esa angustia de lo Unheimlichkeit en un sujeto súbitamente privado de su Heim, de ese "en casa" que le suministra su punto de vista sobre el mundo (Chemama y Vandermersch, 2004, p. 147).

Podríamos decir, entonces, que la pérdida de referentes simbólicos o imaginarios que permiten al sujeto reconocerse o hacerse familiares provoca ese sentimiento de despersonalización. Cuando desaparece esa ventana del fantasma, en el que la realidad nos parece familiar, es cuando el sujeto se desarma y se da de bruces contra el mundo. El que está preso del sentimiento de lo siniestro siente lo familiar como lo más extraño: "el despersonalizado ya no dispone de ese lugar - que es también el de la falta en el Otro- a tal punto que su imagen en el espejo le hace el efecto de un doble, de un usurpador" (p. 148).

Lo que asegura nuestra existencia es ante todo la existencia de un deseo, esa falta en nosotros que atribuimos a Otro que nos completa, y cuando esa falta no está, entonces eso íntimo en nosotros nos resulta oscuro. Todo se juega en el 
modo como asumimos eso íntimo, aunque extraño, que habita en nosotros y que hemos identificado en los sueños. Quisiéramos culminar con una hipótesis sobre la existencia de ese sentimiento de pérdida de los referentes simbólicos e imaginarios en una violencia primordial, como la que hemos visto en el narcisismo unido al masoquismo primario.

Ese sentimiento de despersonalización es la pérdida de puntos de referencia y la hemos visto desde la carta de Einstein como psicosis colectiva en el cuestionamiento de la guerra. El sentimiento de extrañeza puede surgir como un anuncio o anticipo de una escisión completa de la personalidad, el repudio de una parte de la personalidad o del yo, llamada la doble conciencia. Esto es lo que actualmente se llama la pérdida de reconocimiento. Cuando una conciencia se desdobla en la otra y se somete ante el miedo a morir, puede entregarse a esa despersonalización propia de todos los fenómenos de masa.

Recordemos que la psicología de las masas de Freud postula esa pérdida de identidad de las llamadas masas artificiales, las que tienen un conductor y son difíciles de disolver - partidos, ejércitos, iglesias - como distintas a las masas espontáneas sin conductor y fácilmente solubles en algo similar a la enajenación que se sufre en el enamoramiento, la seducción o la hipnosis colectiva. Las relaciones amorosas son la esencia del alma de las masas; dice más precisamente Freud:

La hipnosis se distingue del enamoramiento por la ausencia de tendencias sexuales directas. Del otro lado la hipnosis está tan cerca de la masa con su fascinación por el líder que se puede decir que constituye una formación colectiva de dos.

Puede reconocerse en la cita anterior esa resonancia del fanatismo de las masas que pueden pasar a esa escisión o formación colectiva de dos o finalmente al llamado estado de naturaleza donde las masas se vuelven hordas sin conductor sometidas a una especie de hipnosis o, mejor, vecinas a la psicosis colectiva.

Nos reencontramos con el mismo cuestionamiento de Einstein a Freud sobre el desencadenamiento de la guerra. La hipótesis que anunciamos es la de una vuelta a esa horda primitiva sin conductor - masa asesina y fanatizada-, cuyos lazos libidinales se disuelven y terminan por enloquecerla. Es lo que Freud 
llama un sentimiento de pánico o de pavor, en el cual se mezclan sentimientos de soledad y abandono, ligados al debilitamiento de esos lazos constitutivos de las masas y que identificamos como angustia ante el abandono y sometimiento al gran Otro que los pueda rescatar de esa despersonalización.

Finalmente, Freud identifica ese sentimiento de rescate de la pérdida de sus lazos merced al sentimiento sustitutivo de hostilidad, incluso de odio a quienes no son miembros de la masa.

En una palabra, hemos identificado en el fenómeno de la psicología de las masas y su potencial desidentificación con sus referentes simbólicos e imaginarios, una vuelta del ideal del Yo de la cultura al Yo ideal propio del estado de naturaleza. El narcisismo colectivo de los pueblos o el individual de un yo particular se parecen en que vuelven a esa omnipotencia del pensamiento, que vimos en la psicosis del autoerotismo individual o de la psicosis colectiva.

Ambos modos regresivos son un retorno al estado de naturaleza latente que amenaza con volver, como todo lo reprimido primordial. Se debe postular entonces una violencia en lo real anterior —crueldad siniestra- que amenaza con volver siempre a destruir todos los lazos libidinales. La pulsión de muerte se ha instalado como fundamento del vínculo social, y la crueldad y la tortura que parecían privativas de nuestros antepasados es resucitada del modo anunciado por Nietzsche como método inicial de educar a los pueblos primitivos. Violencia primordial que, como había dicho el autor de Más allá del bien y el mal está presente en toda cultura superior: "Casi todo lo que llamamos cultura superior se basa en la espiritualización y profundización de la crueldad" (Nietzsche, Mas allá del bien y el mal, p. 229).

El hombre ama y odia al padre de la ley; lo ama porque tiene que parecerse a él, pero lo odia porque él es el que lo separa del deseo primero $y$, por eso, todo hombre es ambivalente ante la ley y toda ley siempre será para el hombre una forma de violencia, y sí habrá violación permanente de las leyes, porque entre más leyes se les pongan a los hombres, más intentarán violarlas. Un ser llamado anómalo, como el marqués de Sade, podría ser el profeta de nuestra modernidad, porque él había hablado de nuevo en el lenguaje de Edipo; Sade en su perversión no es más que 
el reverso de la moral, y el imperativo sádico "goza, goza, goza" es el reverso del imperativo moral kantiano "contrólate, contrólate, contrólate". El imperativo de Sade es un imperativo de goce, el imperativo de Kant es un imperativo moral: sé autónomo, ponte leyes, hazte tu propia ley; pues Sade dice, si me quiero hacer mi propia ley, mi propia ley es gozar. Y, por lo tanto, él viola, como Edipo, todos los secretos de la naturaleza, por eso es incestuoso y parricida y asume crímenes que traen la violación de esas normas.

El superyó o la conciencia moral no es más que la herencia del Edipo en cada uno de los hombres. Él manda gozar y violar la ley para reafirmar su poderío. Une en sí mismo esa tensión entre la pulsión de muerte y la de vida. Esta ambivalencia se repite como un destino siniestro de ese conflicto insalvable intrínseco a todo lo humano: el conflicto es insuperable.

La ambivalencia de estas pulsiones ante la ley es el motor de esta lucha insalvable frente a todo ordenamiento positivo y tiene la consecuencia ética sustancial: vivimos en el malestar de la cultura y no en la ética del bienestar. La felicidad como un estado permanente no existe y solo se da en los estados de contraste de situaciones.

No se trata solamente de reconocer que los hombres no tienen una aptitud cultural nata, sino que se trata de cambiar la actitud cultural ante la muerte. Los humanos convivirían mucho mejor entre ellos si aceptasen la delgada corteza de la civilización donde coexisten los estadios más arcaicos de la especie con sus conquistas civilizatorias más logradas. Somos contemporáneos del animismo, la magia y la omnipotencia del pensamiento. De allí que llevemos adentro el mismo asesino y depredador de la naturaleza capaz de romper todos los lazos libidinales colectivos en su intento de apoderamiento del mayor número de bienes.

La diferencia esencial entre los humanos está entonces entre los que aceptan vivir el deseo dentro del deseo del Otro y, por ende, aceptan las instituciones de la cultura como reguladoras de la frustración o de su falla original, y los que resienten la cultura y se aferran al goce perverso de la Cosa en cuya consecución alucinan ese caos así sea al precio de la muerte, la destrucción sádica del otro y la autodestrucción narcisista y masoquista primaria. Empezamos a morir desde el mismo momento 
en que nacemos y, aunque nuestro inconsciente no pueda representarse su propia muerte, sí nos vemos forzados a vivirla en cada muerte cotidiana. Algo se muere en mí todos los días, decía el poeta moderno, y si quieres vivir, prepárate para la muerte, decían los antiguos. Pues si nadie escapa al conflicto mortal de sus pulsiones y ningún animal es tan siniestro como el hombre, entonces el precepto ético básico de lo humano seguirá siendo: haz todo lo necesario para soportar la vida.

\section{Resultados derivados de esta perspectiva filosófico-psicoanalítica}

Hemos tratado de indagar sobre la relación entre las pasiones y la guerra desde la primera meditación moderna sobre este vínculo esbozado por Hobbes desde su hipotético estado de naturaleza, y hemos intentado seguir el curso de esas ambivalentes pasiones que mueven tanto a la paz como a la guerra. Hobbes ha encontrado en la razón natural o en esos teoremas de las leyes naturales una primera forma de salir de ese círculo infernal de la competencia y la desconfianza universal entre los hombres que los sume en la venganza -latente y patente- como amenaza constante de muerte violenta. Pero ese mismo miedo a morir ha venido a convertirse como motor de la angustia y la impotencia en una valiosa ayuda para hacer emerger la razón o el cálculo racional que posterga la ejecución de las pasiones en una suerte de principio de realidad sustentado por la fuerza de un pacto colectivo. Ese hombre artificial construido por la voluntad como una inmensa máquina o macrocuerpo obliga a sus órganos a aceptar las reglas de un soberano, que monopolice la fuerza de manera legítima bajo el imperio de una misma ley llamada Estado.

Freud parte de esas premisas antropológicas sobre la lucha entre las pasiones y la ley ahora denominada por él conflicto entre pulsiones $y$ cultura. El estado de naturaleza de Hobbes es trasladado a ese estado primordial de las pulsiones en ese mito originario del padre de la horda primordial asesinado como reacción a su dominio despótico sobre esas pulsiones primordiales llamadas inicialmente por Freud amor y necesidad (eros y ananké), como responsables de esa búsqueda de satisfacción a sus tendencias primordiales. Para Freud, el círculo de la venganza no se supera 
con el miedo a una muerte violenta, sino con el miedo a repetir un crimen primordial resultado más bien de la venganza contra el padre todopoderoso.

Freud invierte el orden: primero fue el crimen y luego el miedo a repetir las condiciones que le dieron lugar. El goce total de todas las pulsiones lleva a la muerte y, por ello, ella es más originaria incluso que el llamado instinto de conservación. Eros y ananké son reemplazados por eros y tánathos como pulsiones primordiales.

De esa dialéctica ineluctable entre vida y muerte ha emergido la hipótesis de que la vida misma no es más que un largo camino hacia la muerte y que toda pulsión aspira a retornar a ese estado primero inorgánico de supuesta plenitud donde no existe falta ni régimen que la regule. La muerte precede a la vida como el caos antecede al orden y el sinsentido al sentido.

La cultura como morada humana no es más que un intento siempre provisorio por separarnos de ese estado de naturaleza. Esto es lo que se denomina la cosa freudiana o el deseo de ir más allá de toda representación construida por la historia de los sentidos humanos. Una ambivalencia fundamental decide la suerte del animal simbólico: $\mathrm{o}$ acepta esa alienación o frustración primaria de sus pulsiones propia de toda cultura edificada sobre la imposible vuelta a un imaginario estado de naturaleza, o se aferra a ese imaginario estado de omnipotencia del pensamiento donde alucina el reino del Uno primordial, estado indiferenciado de goce absoluto sin cortapisa alguna para las pulsiones en una supuesta armonía natural o estado de adaptación natural sin fallas ni falta estructural alguna.

Este es el dilema primordial que debe resolver toda ética y estética de la vida. O se acepta la muerte como finitud y falta primordial propia de todo deseo del Otro, o se aspira a la omnipotencia del pensamiento que no acepta falla alguna para ese ilusorio paraíso de la plenitud natural llamada cosa. Los humanos no tienen otra opción entre estado natural o cultura. O se acepta el deseo como falta o se aferra al goce primordial de la plenitud ilusoria.

De aquí procede la segunda diferencia central entre el conflicto pasional con la ley visto desde Hobbes y sus herederos contractualistas con el enfoque psicoanalítico. Mientras el filósofo empirista veía en el 
miedo a morir la pasión fundamental capaz de provocar la renuncia a las pasiones para acceder a la razón calculadora de ellas, Freud descreía de un orden o acuerdo duradero así fuera protegido por el poder de la espada. Educar, gobernar y amar son profesiones imposibles porque suponen una superación de la ambivalencia de los sentimientos ante un padre o representante de la ley soberana acordada. Para Freud, el placer y la utilidad cómoda no rigen ese equilibrio precario vital ni la imposible armonía de esas pulsiones con cualquier ley cultural. No es la ética del bienestar o el placer de los bienes lo que adapta a la vida, sino ese más allá del placer propio de la pulsión de muerte la que provoca el malestar de la cultura y es permanente insatisfacción por la frustración original de las pulsiones. La eterna oscilación entre el yo ideal y el ideal del yo, en procura siempre de recuperar esa sensación de omnipotencia perdida de un paraíso original de un yo ideal completo, implican que la persistencia de esa añoranza y la tendencia a la destrucción de los lazos libidinales permanece latente en toda masa artificial y mucho más en las espontáneas multitudes que cíclicamente irrumpen en la escena social y política. Para Freud es esta la raíz de la violencia primordial: el haber sido extrañado de esa primera morada uterina y haber sofocado esa unidad inicial por los sustitutos imaginarios y simbólicos de la cultura humana. El conflicto no cesa así desaparezcan las causas primordiales de la escasez de recursos y el monopolio privado de los medios de producción sea socializado. $\mathrm{Ni}$ las invenciones de la técnica ni los paraísos artificiales de la droga, ni siquiera el amor erótico o sublimado, logran desterrar la agresividad humana y la siniestra tendencia a regresar a los orígenes criminales de provocar la ruptura de toda ley. La anomia es una tendencia latente capaz de romper todas las alianzas propias de la familia, la sociedad civil y el Estado.

Por último, hemos descubierto esta tendencia al narcisismo primario y al masoquismo primario como una satisfacción libidinal que se nutre de la transgresión de todos los límites normativos. La eterna lucha entre valores y normas se agudiza en el narcisismo de las culturas y el apego a sus valores matriciales. Los lazos de la sangre y sus potencias tectónicas que se ven en los mitos, como el de Antígona, implican que 
el poder de esos significantes, como el bien, la verdad y la belleza, pueden destruir cualquier ordenamiento positivo y dar vuelta a la crueldad inicial de lealtades a lazos naturales y sanguíneos. En suma, esos poderes de naciones, razas, credos y creencias valorativas no desaparecen nunca por más homogéneos que sean los lazos libidinales de los llamados bienes civilizados.

Esta es la básica diferencia entre los seres ligados por la eticidad humana. Su división es entre los que aceptan ser sujetos del deseo por devenir como tales ante el deseo de Otro, estado que prefigura la muerte ante la cosa presente desde siempre en el animal simbólico, y al aceptar su separación vital aceptan su destino mortal; y la de los que no aceptan la muerte como posibilidad originaria de toda vida deseante, $y$, al aferrarse imaginariamente a una vida sin muerte, provocan en forma siniestra la transgresión constante de esta discontinuidad con un ideal estado de naturaleza al que intentan volver como goce sin falta. Deseo del Otro y goce de la cosa son los dos principios divisorios entre los resentidos de la vida, y los deseantes que aceptan esquematizar el caos y regular su falta en el malestar de la cultura. Sustituir la violencia del caos primordial por una violencia simbólica e intentar salir del sinsentido para crear un sentido de ley, así sea con ambivalencia ante ella. Este es el dilema ético vital: aferrarse a ese anhelo de un Uno primordial cuya identidad nihilista anula la diferencia, o aceptar la Otredad de la finitud y la falta al intentar construir una morada, así esta morada esté rota. Ningún animal más extraño que el hombre, pero ahora sabemos que nada lo hace más extraño que el apego entrañable de tornar a la morada materna, cuna y muerte de la vida.

\section{Referencias}

Chemama, R. y Vandermersch, B. (2004). Diccionario del psicoanálisis. Buenos Aires: Amorrortu.

Nietzche, Friederich. (2010). Más allá del bien y del mal. México: Ediciones leyenda.

Nietzche, Friederich. (2007). El nacimiento de la tragedia. Madrid: Biblioteca Nueva.

Freud, S. (1979). Interpretación de los sueños. En Obras completas (t. V). Buenos Aires: Amorrortu. 
Hobbes, T. (1994). Leviatán. Barcelona: Altaya.

Roudinesco, E. y Plon, M. (2006).

Diccionario de psicoanálisis. Buenos Aires: Paidós. 